\title{
ENERGY AND WATER BUDGETS OF LARKS IN A LIFE HISTORY PERSPECTIVE: PARENTAL EFFORT VARIES WITH ARIDITY
}

\author{
B. Irene Tieleman, ${ }^{1,4}$ Joseph B. Williams, ${ }^{2}$ AND G. Henk Visser ${ }^{1,3}$ \\ ${ }^{1}$ Zoological Laboratory, University of Groningen, P.O. Box 14, 9750 AA Haren, The Netherlands \\ ${ }^{2}$ Department of Evolution, Ecology and Organismal Biology, Ohio State University, 1735 Neil Avenue, \\ Columbus, Ohio 43210 USA \\ ${ }^{3}$ Center for Isotope Research, University of Groningen, Nijenborgh 4, 9747 AG Groningen, The Netherlands
}

\begin{abstract}
We compared physiological, demographic, and ecological variables of larks to gain insights into life history variation along an aridity gradient, incorporating phylogenetic relationships in analyses when appropriate. Quantifying field metabolic rate (FMR) and water influx rate (WIR) of parents feeding nestlings as measures of parental effort, we found that parental FMR and WIR of larks decreased with increasing aridity. Water and energy requirements of 6-8 d old nestlings were reduced in desert species. Nestling growth rate, clutch size, and number of clutches decreased with increasing aridity, and nest predation rates increased with increasing aridity. We combined FMR and WIR of parents and chicks, energy and water accumulated during growth, and brood size to establish energy and water budgets of parent-brood units. Parent-offspring energy budgets equaled $261 \mathrm{~kJ} / \mathrm{d}$ for Hoopoe Lark, $164 \mathrm{~kJ} / \mathrm{d}$ for Dunn's Lark, $388 \mathrm{~kJ} / \mathrm{d}$ for Skylark, and $347 \mathrm{~kJ} / \mathrm{d}$ for Woodlark, a $27 \%$ reduction in the desert species when taking into account mass differences. Family unit WIRs were $46.6 \mathrm{~g} / \mathrm{d}$ for Hoopoe Lark, $37.3 \mathrm{~g} / \mathrm{d}$ for Dunn's Lark, $101.6 \mathrm{~g} / \mathrm{d}$ for Skylark, and $83.2 \mathrm{~g} / \mathrm{d}$ for Woodlark. Parent-brood units of arid-zone species used $28-51 \%$ less water per gram mass than species from mesic areas. These results support the hypothesis that decreasing food and water availability favor lower energy and water requirements of parents and young, reduced growth rates, and smaller clutch sizes with increasing aridity. The decrease in parental effort with increasing aridity might reflect a lower fitness value of a single brood for arid-zone species than for larks from mesic habitats, suggesting that the probability of adult survival is higher in arid than in mesic areas.
\end{abstract}

Key words: Alaudidae; aridity; clutch size; desert; field metabolic rate; growth rate; larks; life history; nest predation; water influx rate.

\section{INTRODUCTION}

A central tenet of life history theory is that current reproductive investment is traded off against residual reproductive value (Williams 1966, Stearns 1992). This trade-off, or cost of reproduction, is fundamental in predicting the optimal life history in a variety of environments. The difficulty of obtaining direct measures of fitness costs to demonstrate a cost of reproduction has stimulated investigators to find currencies related to fitness. A frequently used measure of current reproductive investment is parental effort, the proportion of available resources devoted to reproduction as opposed to growth and maintenance (Reznick 1985) that can be expressed in terms of energy, assuming that life history trade-offs are the result of energy allocation (Drent and Daan 1980, Bryant 1988). Because separating resources allocated to reproduction and to maintenance is problematic in field studies on birds, investigators have used total daily energy expenditure as a measure of parental

Manuscript received 12 March 2003; revised 15 September 2003; accepted 19 September 2003. Corresponding Editor: T. D. Williams.

${ }^{4}$ Present address: Department of Biology, University of Missouri at St. Louis, 8001 Natural Bridge Road, St. Louis, MO63121-4499 USA. E-mail: tielemani@umsl.edu effort (Bryant 1988, Weathers and Sullivan 1989, Tinbergen and Verhulst 2000). In this study we use parental energy expenditure and water flux in the field as proxy for parental effort, and we relate these variables to basal metabolic rate (BMR) and total evaporative water loss (TEWL) from laboratory studies. In addition, we investigate variation in clutch size as an independent measure of parental effort.

Whereas clutch size is ultimately determined by parental fitness allocation to current and future reproduction (Perrins and Moss 1975, Boyce and Perrins 1987), it has been explained at a proximate level by environmental conditions such as risk of nest predation and food availability. Lack (1968) argued that nestling mortality due to predation could be reduced by shortening the nestling period, but that this would require faster growth and result in higher energy demands of the young. He suggested that growth rates are a compromise between risk of predation and food availability. Environments with a higher predation risk should select for faster growing young, and thereby force parents to raise fewer young per nesting attempt, assuming that parents are limited in the amount of food per day that they can deliver to their brood. In contrast with this prediction, however, high nest predation, slow 

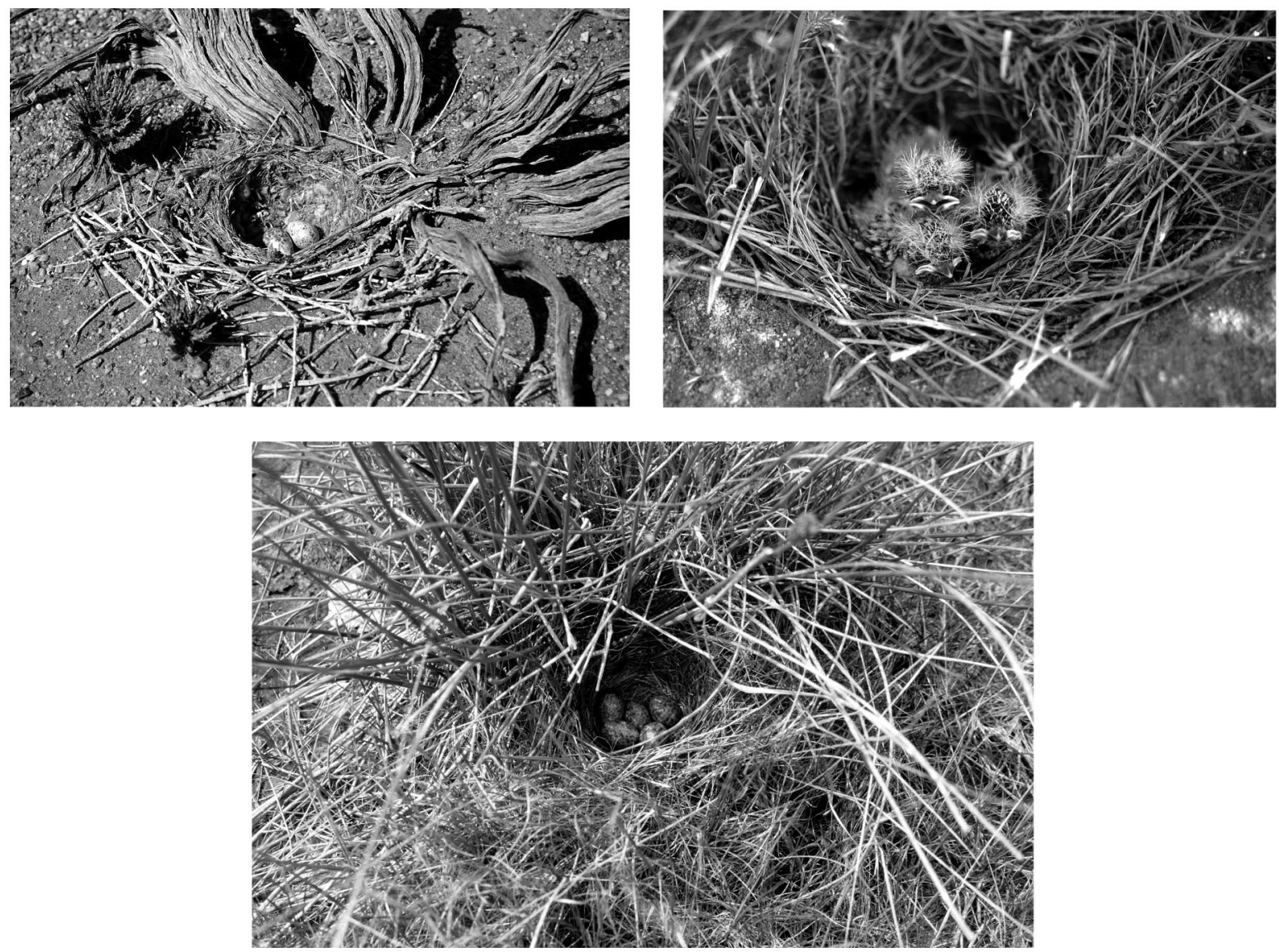

Plate 1. Hoopoe Larks (left) and Dunn's larks (right) in the Arabian Desert, the arid extreme of the aridity gradient, generally produce 2-3 chicks per brood, whereas Skylarks (bottom) in the Netherlands, representing the mesic extreme, regularly lay $4-5$ eggs per next. Photo credit: B. Irene Tieleman.

growth, and small broods occur together in tropical birds, whereas low nest predation, fast growth, and large broods characterize temperate zone species (Skutch 1966, Ricklefs 1979, Martin et al. 2000). Additional insights may be obtained by understanding the relationships between growth rate, clutch size, and nest predation along an aridity gradient ranging from hot dry deserts to cool moist environments (see Plate 1).

Deserts, the one extreme of our aridity gradient, are characterized by high ambient temperatures $\left(T_{\mathrm{a}}\right)$, unpredictable, low rainfall, and reduced primary productivity, resulting in limited food and water availability for their inhabitants. In such environments, natural selection potentially favors individuals with low rates of energy expenditure and water loss (Louw and Seely 1982, Williams and Tieleman 2001, Tieleman et al. 2003a). However, during the reproductive season, parents not only provide food and water for themselves, but also for their offspring, and may need to elevate their own energy and water requirements in order to produce young. Whereas the amount of energy and water that can be invested per brood may be determined by the time available for foraging and the availability of food and water, the number of chicks that can be reared per brood depends also on the daily energy and water requirements per young. Reductions in these requirements could be accomplished by reducing nestling metabolism, growth rate, and evaporative and excretory water losses (Klaassen and Drent 1991). To date, few studies have investigated how energy and water are allocated to different components of the energy and water balance of a parent-brood complex in different environments.

Across-species comparisons supported the hypothesis that arid-zone birds have, on average, lower TEWL, BMR, and field metabolic rate (FMR) than nondesert species (Williams 1996, Tieleman and Williams 2000), also when taking into account phylogeny (Felsenstein 1985). Results for comparisons of field water influx rate (WIR) were equivocal, with conventional analysis showing differences between desert and nondesert species, but results from independent contrast analysis were not (Tieleman and Williams 2000).

Broad-scale interspecific comparisons of metabolism and water loss have the inherent problem that species differ not only in habitat but also in phylogenetic back- 
ground, diet, and behavior (Bennett 1988, Leroi 1994). In addition, the use of a dichotomous categorization of environments might obscure useful biological information. We have confined our work to species in the lark family (Alaudidae) that are all ground-foraging birds with similar diets and behaviors. Knowledge of the phylogeny of larks allows us to take into account phylogenetic relatedness in analyses (Tieleman et al. 2003a). Larks have the additional advantage that different members of this family occur in environments ranging from hot, dry deserts to cool, moist grasslands. Following the approach of climatologists, who have long recognized that environments form a continuum with respect to meteorological parameters, we mapped our data on an environmental continuum of aridity. Aridity is directly related to primary productivity (Emberger 1955) and provides a proxy for the combined selection pressures that animals experience with increasing aridity, including decreasing water and food supply, and increasing temperatures (Tieleman et al. 2003a).

Among larks, BMR and TEWL decrease with increasing aridity (Tieleman et al. 2003a). The variation in BMR and TEWL cannot be explained by phylogeny (Tieleman et al. 2003a), or attributed to acclimatization to temperature, food availability, or day length, and is likely to have a genetic component (Tieleman et al. $2003 b$ ). These laboratory results gain evolutionary significance if one finds consistent patterns in the field, where natural selection operates on a combination of physiology and behavior.

In this study we compare physiological, demographic, and ecological variables of a series of lark species to gain insights into the connection between life history and physiology in environments ranging from hot, arid deserts to cool, moist grasslands. We quantified FMR and WIR of parents feeding nestlings as a measure of parental effort, and investigated if nestling FMR, WIR, and growth rate vary with environmental aridity. This information allows construction of energy and water budgets for the parent-offspring complex, and provides an integrative perspective of the various components on which natural selection might act. We tested the hypotheses that energy and water requirements of the parent-offspring complex and parental effort decrease with increasing aridity. In addition, we measured clutch size, nestling growth rate, and nest predation risk to explore how these variables vary with decreasing food availability in the environment. We predicted that, with increasing aridity, environments provide less nest cover, resulting in higher nest predation rates, and less food, resulting in decreased clutch size and growth rate. We expected that low food availability can override the effect of high predation risk that favors increased growth rate (Lack 1968).

\section{Methods}

Study species and areas

We studied Hoopoe Larks (Alaemon alaudipes), Dunn's Larks (Eremalauda dunni), Bar-tailed Desert
Larks (Ammomanes cincturus), and Black-crowned Finchlarks (Eremopterix nigriceps) during the breeding seasons of 1998 and 2001 in Mahazat as-Sayd, a nature reserve in the Arabian Desert $\left(22^{\circ} 15^{\prime} \mathrm{N}, 41^{\circ} 50^{\prime} \mathrm{E}\right)$. Skylarks (Alauda arvensis) and Woodlarks (Lullula arborea) were studied from April to June 2002 in Aekingerzand, a nature reserve in The Netherlands $\left(52^{\circ} 52^{\prime} \mathrm{N}, 06^{\circ} 20^{\prime} \mathrm{E}\right)$. Laboratory measurements of BMR and TEWL were made during summer in the period 1998-2001 for larks in Saudi Arabia, and in the summer of 2000 for larks in the Netherlands (Tieleman et al. 2003a). Literature data of eight lark species from hyperarid, arid, and semi-arid areas in Namibia, South Africa, Israel, Kazachstan, and Spain complete our aridity gradient represented by a total of 14 species of larks. Aridity indices and climate data for the geographical regions of all larks in this study have been reported in Tieleman et al. (2003a).

\section{Doubly labeled water}

Measurements of WIR and FMR were obtained using the doubly labeled water (DLW) technique, in which the rate of decline of ${ }^{2} \mathrm{H}$ in the body water pool provides a measure of WIR (Nagy and Costa 1980) and the loss rates of both ${ }^{2} \mathrm{H}$ and ${ }^{18} \mathrm{O}$ yield an estimate of $\mathrm{CO}_{2}$ production (Lifson and McClintock 1966, Nagy 1980, Speakman 1997). For details on capture, injection, blood sampling, and recapture, see Appendix A.

Isotope ratios of ${ }^{2} \mathrm{H}:{ }^{1} \mathrm{H}$ and ${ }^{18} \mathrm{O}:{ }^{16} \mathrm{O}$ were determined in duplicate (initial) or triplicate (final) for each sample at the Center for Isotope Research, University of Groningen (Visser and Schekkerman 1999). The coefficient of variation of the duplicate or triplicate measurements was $<2 \%$. We calculated water influx with Eq. 3 in Nagy and Costa (1980), and corrected for isotope fractionation effects assuming an evaporative water loss of $25 \%$ and a fractionation factor of 0.941 (Eq. 7.6 in Speakman [1997] and Visser et al. [2000]). Total body water was estimated from isotope dilution. Rates of $\mathrm{CO}_{2}$ production were calculated with Eq. 7.17 in Speakman (1997).

$\mathrm{CO}_{2}$ production can be converted to energy expenditure when the composition of the diet is known (Gessaman and Nagy 1988, Weathers and Sullivan 1989). We assumed that seeds contain $13.5 \%$ protein, $5.1 \%$ lipid, and $81.4 \%$ carbohydrate (MacMillen 1990) and that insects contain $62.0 \%$ protein, $14.9 \%$ lipid, and $15.0 \%$ carbohydrate (Williams and Prints 1986). We assumed for all species of larks that adults during the breeding season consume a diet of $90 \%$ insects and $10 \%$ seeds (B. I. Tieleman and J. B. Williams, personal observation), and calculated a conversion factor of $24.16 \mathrm{~kJ} / \mathrm{L} \mathrm{CO}_{2}$ based on conversion factors for protein, fat, and carbohydrate metabolism (Gessaman and Nagy 1988). For nestlings, which consume a diet exclusively of insects, we used a conversion factor of $24.39 \mathrm{~kJ} / \mathrm{L}$ $\mathrm{CO}_{2}$. 
TABLE 1. (A) Body mass, field metabolic rate, water influx rate of parent birds, and average number of chicks per nest that were fed by parents of six species of larks, and (B) field metabolic rate and water influx rate of 6-8 d old nestlings of five species of larks.

\begin{tabular}{|c|c|c|c|c|c|c|c|c|c|c|}
\hline \multirow[b]{3}{*}{ Species } & \multirow{2}{*}{\multicolumn{2}{|c|}{ Mass (g) }} & \multirow{2}{*}{\multicolumn{2}{|c|}{$\mathrm{FMR}(\mathrm{kJ} / \mathrm{d})$}} & \multirow{2}{*}{\multicolumn{2}{|c|}{ WIR (g/d) }} & \multirow[b]{3}{*}{$n$} & \multicolumn{3}{|c|}{ Nests } \\
\hline & & & & & & & & No. chicks & & \\
\hline & Average & $\mathrm{SD}$ & Average & SD & Average & SD & & per nest & SD & $n$ \\
\hline \multicolumn{11}{|l|}{ A) Parent birds } \\
\hline Bar-tailed Desert Lark & 16.5 & 1.78 & 34.9 & 7.41 & 6.4 & 0.99 & 3 & 2.0 & 1.41 & 2 \\
\hline Black-crowned Finchlark & 13.6 & 0.04 & 34.3 & 1.61 & 4.9 & 0.68 & 2 & 2.5 & 0.71 & 2 \\
\hline Dunn's Lark & 21.5 & 1.80 & 42.1 & 7.32 & 8.1 & 2.40 & 20 & 2.7 & 1.16 & 10 \\
\hline Hoopoe Lark & 39.8 & 6.30 & 70.4 & 13.96 & 12.7 & 2.85 & 13 & 2.7 & 0.49 & 7 \\
\hline Skylark & 33.6 & 3.80 & 101.4 & 14.82 & 23.6 & 2.92 & 12 & 3.5 & 0.53 & 8 \\
\hline Woodlark & 27.0 & 1.32 & 82.9 & 10.19 & 16.4 & 3.12 & 12 & 4.0 & 0.82 & 7 \\
\hline \multicolumn{11}{|l|}{ B) Nestlings } \\
\hline Bar-tailed Desert Lark & 12.3 & 1.24 & 15.5 & 1.04 & 6.5 & 0.65 & 2 & & & \\
\hline Dunn's Lark & 13.0 & 1.58 & 22.7 & 3.86 & 7.1 & 1.58 & 4 & & & \\
\hline Hoopoe Lark & 20.4 & 2.34 & 31.1 & 4.98 & 6.2 & 1.00 & 13 & & & \\
\hline Skylark & 21.1 & 1.48 & 45.5 & 8.28 & 14.8 & 3.53 & 6 & & & \\
\hline Woodlark & 17.5 & 1.41 & 36.1 & 3.95 & 11.6 & 1.45 & 10 & & & \\
\hline
\end{tabular}

\section{Nest monitoring}

We visited nests with eggs or young at 1-6-d intervals to determine nest survival. Whenever possible, we inspected nests from a distance or from the car, minimizing the risk to leave cues for predators. When all eggs or nestlings disappeared we assumed that predation was the cause. Calculations of nest mortality were made using the Mayfield method (Mayfield 1975, Johnson 1979) for the total nest period, including laying, incubation, and nestling phase. Daily survival rate was calculated as DSR $=1-$ daily nest mortality.

\section{Statistical analysis and phylogenetic effect}

We used General Linear Models procedures in SPSS 10.0 (SPSS 1999) for analysis of variance (ANOVA) and covariance (ANCOVA) to investigate differences in FMR and WIR among four species from the two extremes of our gradient. We tested the two-way interaction terms and removed them from the model when insignificant. After one-way ANOVAs, we used Tukey tests for multiple comparisons (Zar 1996).

In comparisons among species, ANOVA has proven useful because it takes into account intraspecific variation. However, this approach has been criticized because each species is treated as independent, whereas phylogenetic relatedness may cause nonindependence among species (Felsenstein 1985). Regression analysis with average values for species ignore intraspecific variation, but can take into account phylogenetic relationships using phylogenetic independent contrasts (Felsenstein 1985, Garland et al. 1992). In addition to our analyses using ANOVA, we performed regression analysis using species averages taking into account phylogeny when appropriate. For these analyses, we added data on FMR and WIR of the Dune Lark (Williams 2001) to our complete data set, including Bar-tailed Desert Lark and Black-crowned Finchlark for which sample sizes were low (Table 1), and correlated these variables with environmental aridity. We used the phylogeny of larks from Tieleman et al. (2003a), and placed the Thekla Lark, for which the phylogenetic relationships were not established, as sister species to the Crested Lark.

To evaluate whether a phylogenetic effect (sensu Grafen [1989] and Harvey and Pagel [1991]) existed among the larks in this study, we used the test for serial independence (TFSI) to determine if there was a significant positive autocorrelation for mass-adjusted FMR, mass-adjusted WIR, growth rate, clutch size, number of clutches, and daily nest survival (Abouheif 1999, Reeve and Abouheif 1999). In each simulation the topology was randomly rotated 2000 times per iteration and the original data were shuffled 2000 times in order to provide the null hypothesis sampling distribution (Reeve and Abouheif 1999). The test for serial independence is more suitable for smaller data sets than other phylogenetic autocorrelation methods (Cheverud et al. 1985, Gittleman and Kot 1990, Abouheif 1999). If no phylogenetic effect exists, then incorporating phylogeny in statistical methods would be unnecessary (Gittleman and Kot 1990, Björklund 1997, Abouheif 1999). If a phylogenetic effect does exist, this may be attributable to phylogenetic constraint or to ecological factors and corrections for phylogenetic relationships may or may not be appropriate (Westoby et al. 1995). For the cases where we found a phylogenetic effect, we provided results of phylogenetic independent contrast (PIC) analysis using the Phylogenetic Diversity Analysis Package (Garland et al. 1992) in addition to results from conventional statistics. Averages are reported \pm 1 SD unless noted otherwise.

\section{REsUlts}

\section{Field metabolic rate of parents}

We compared FMR of adults feeding 5-8 day old nestlings of four species of larks from arid and mesic 

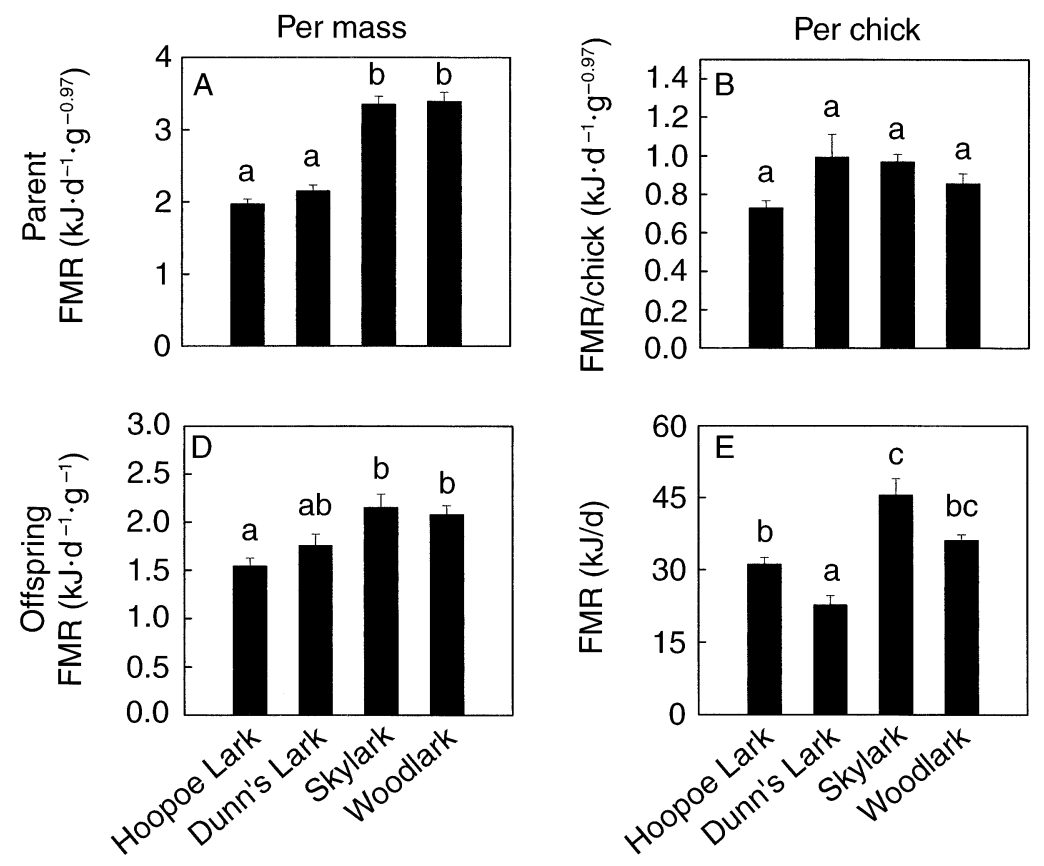


FIG. 1. Field metabolic rate (FMR, mean $\pm 1 \mathrm{SE})$ of $(\mathrm{A}-\mathrm{C})$ parents and $(\mathrm{D}-\mathrm{F})$ nestlings of six species of larks taking into account (A, D) mass differences, (B, E) expressed per nestling, and (C, F) expressed per brood. (F) Metabolizable energy intake of the entire brood, $E_{\mathrm{bro}}$, is the sum of FMR (black) and tissue production (gray). Letters indicate homogeneous subsets based on Tukey tests (significance level: $P=0.05$ ).

environments (Fig. 1C, Table 1A). To adjust for differences in body mass, we divided FMR by mass ${ }^{0.97}$. The exponent 0.97 was the common slope for all species determined by ANCOVA with $\log$ (FMR) as dependent variable, species as fixed factor, and $\log$ (mass) as covariate in a model without interaction term $\left(\log\right.$ (mass) $\left.F_{1,52}=30.67, P<0.0001\right)$, after verifying that the interaction had no significant effect on $\log (\mathrm{FMR})\left(\right.$ species $\times \log ($ mass $\left.) F_{3,49}=0.32, P=0.81\right)$. Mass-adjusted FMR differed significantly between species $\left(F_{3,53}=58.87, P<0.0001\right)$, and a Tukey test indicated that Hoopoe Lark and Dunn's Lark are part of a different homogeneous subset than Woodlark and Skylark (Fig. 1A). Average mass-adjusted FMR of the arid-zone species was $36-42 \%$ lower than of the mesic larks. Because the number of nestlings per nest varied (Table 1A), we calculated parental energy expenditure per chick by dividing mass-adjusted FMR by the number of chicks the parent was feeding, and found no significant differences between species $\left(F_{3,53}=1.84\right.$, $P=0.15$; Fig. 1B). The ratio FMR:BMR varied among species from 1.7 to 2.1 (see Appendix B, Fig. B1). A Tukey test showed significant differences only for Hoopoe Lark compared with Skylark, Woodlark, and Dunn's Lark $\left(F_{3,53}=8.15, P<0.0001\right)$.

\section{Water influx rate of parents}

For comparison of WIR among species, we calculated mass-adjusted values as WIR/mass ${ }^{0.76}$ (Fig. 2C, Table 1A). The exponent 0.76 was the common slope for all species in an ANCOVA with $\log ($ WIR) as dependent variable $\left(\log\right.$ (mass) $F_{1,52}=7.52, P=0.008$ ), after removing the insignificant interaction term from the model $\left(F_{3,49}=0.25, P=0.86\right)$. Mass-adjusted WIR differed significantly among species $\left(F_{3,53}=55.91, P\right.$ $<0.0001)$, and a Tukey test showed homogeneous subsets of the arid-zone larks, Skylark and Woodlark (Fig. 2A). Mass-adjusted WIR for arid-zone larks feeding nestlings was $41-52 \%$ lower than for larks from mesic areas. To compare the WIR of parents per chick, we divided mass-adjusted WIR by the number of nestlings that each parent fed. Parental WIR per chick was similar among most species, with only a significantly higher mass-adjusted WIR per chick in Skylarks compared with the other three species (ANOVA species, $F_{3,53}=$ $5.70, P=0.002$; Fig. 2B). The ratio of WIR:TEWL varied among species $\left(F_{3,53}=21.66, P<0.0001\right)$, and was about $6.8 \times$ TEWL in the mesic species and about $4.2 \times$ TEWL in the arid-zone larks (Appendix B, Fig. B1).

\section{Differences in parental FMR and WIR between sexes?}

To explore if males and females worked equally hard, we used ANCOVA with $\log$ (FMR) or $\log$ (WIR) as the dependent variable, species and sex as fixed factors, and $\log$ (mass) as covariate. Neither $\log ($ FMR $)$ nor $\log ($ WIR $)$ differed significantly between the sexes $\left(\log (\mathrm{FMR}), F_{2,50}=1.31, P=0.28 ; \log (\mathrm{WIR}), F_{2,50}=\right.$ $0.42, P=0.66)$. 

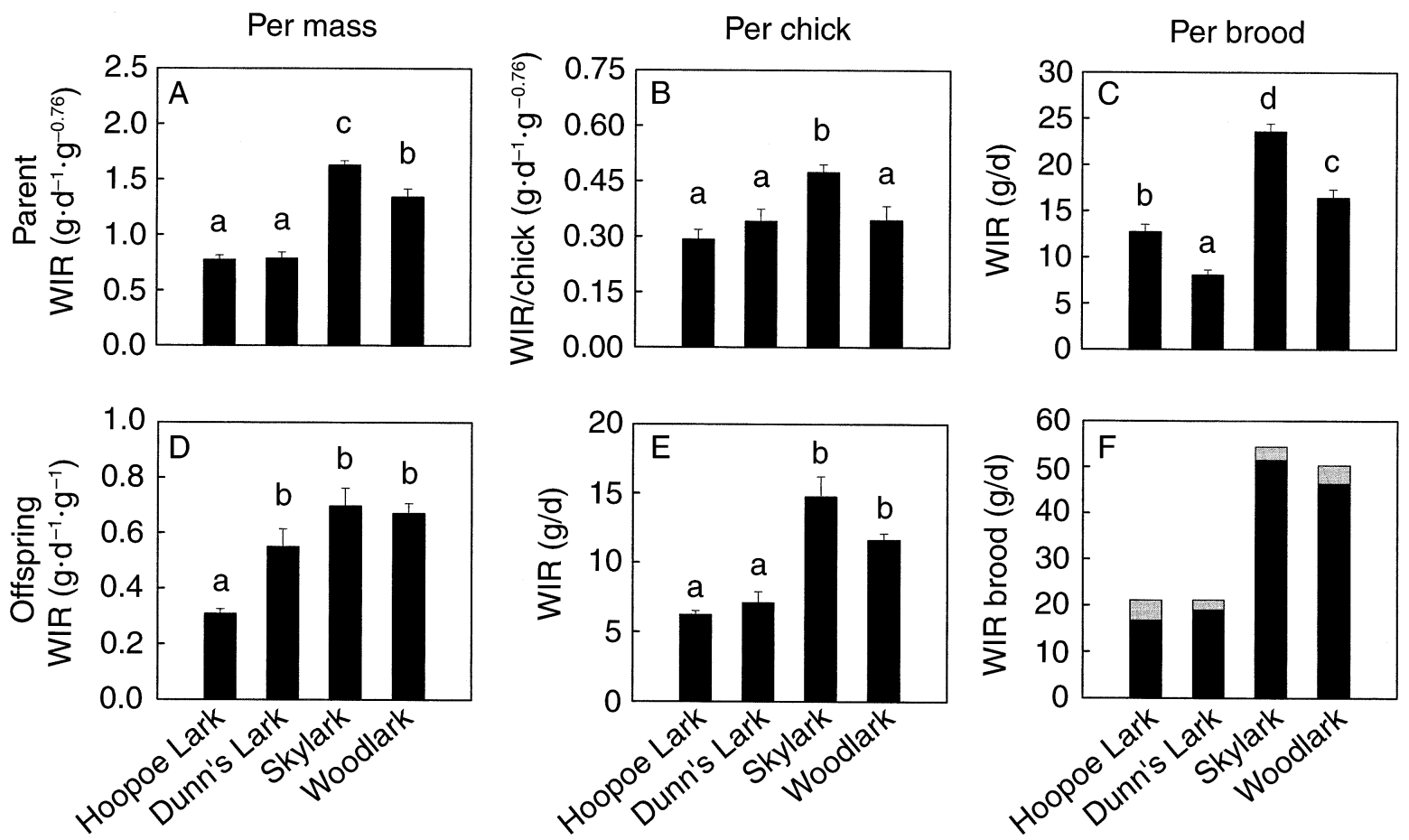

FIG. 2. Water influx rate (WIR, mean $\pm 1 \mathrm{SE}$ ) of (A-C) parents and (D-F) nestlings of six species of larks, (A, D) taking into account mass differences, (B, E) expressed per nestling, and (C, F) expressed per brood. (F) Water requirements of the entire brood are the sum of water influx rate (black) and water accumulated in tissue (gray). Letters indicate homogeneous subsets based on Tukey tests (significance level: $P=0.05$ ).

\section{Field metabolic rate of nestlings}

We compared energy expenditure of 6-8 d old nestlings among four species of larks from arid and mesic environments (Fig. 1E, Table 1B). In larks, nestling energy expenditure reaches an asymptote at day 6-8 (Williams 2001), and therefore enables calculation of peak energy demand of the brood. In an ANCOVA with $\log (\mathrm{FMR})$ as the dependent variable, species as fixed factor, and $\log$ (mass) as covariate, the interaction between species and $\log$ (mass) was insignificant $\left(F_{3,25}=\right.$ $0.97, P=0.42)$. We found no significant influence of $\log$ (mass) $\left(F_{1,28}=0.47, P=0.50\right)$, but a significant effect of species on $\log (\mathrm{FMR})\left(F_{3,28}=11.28, P<\right.$ $0.0001)$. Therefore, we removed mass from the model and investigated differences in FMR between species (Fig. 1E). Mass-specific FMR (kilojoules per day per gram) of nestlings also differed among species $\left(F_{3,29}\right.$ $=8.84, P<0.0001)$ and was $16-28 \%$ lower in the arid-zone species than in the mesic larks (Fig. 1D).

\section{Water influx rate of nestlings}

For a comparison of water requirements of 6-8 day old nestlings (Fig. 2E, Table 1B), we tested the effect of species and $\log$ (mass) on $\log$ (WIR) with an ANCOVA and found no significant effects of the interaction $\left(F_{3,25}=0.63, P=0.60\right)$ or of $\log$ (mass) $\left(F_{1,28}\right.$ $=0.17, P=0.68)$, but a significant effect of species $\left(F_{3,28}=44.78, P<0.0001\right)$. After removing mass from the analysis, we used a Tukey test with WIR as dependent variable to investigate differences between species. Nestling Woodlarks and Skylarks had indistinguishable WIR (grams per day), and values for these two species were higher than those for the arid-zone species (Fig. 2E). Mass-specific WIR (grams of water per day per gram of body mass) differed significantly among species $\left(F_{3,29}=29.521, P<0.0001\right)$. Hoopoe Lark nestlings had a lower mass-specific WIR than the other three larks (Fig. 2D).

\section{Nestling growth rates along an aridity gradient}

We measured body mass of known-age nestlings to determine their growth rates (Fig. 3). Growth is commonly described by a logistic curve, $W(t)=A /(1+$ $\left.\exp \left[-K\left(t-t_{\mathrm{i}}\right)\right]\right)$, where $W(t)$ is the mass (grams) at age $t$ (day), $A$ is the asymptote of the growth curve (grams), $K$ is the growth rate constant $\left(\right.$ day $\left.^{-1}\right)$, and $t_{\mathrm{i}}$ is the inflexion point or age at maximal growth rate (day) (Ricklefs 1979). Some chicks of the desert species did not grow and starved to death (Fig. 3). These data were excluded when we constructed growth curves (Appendix C, Table C1).

To explore if growth rates are correlated with aridity, we added data for Dune Lark nestlings from the Namib Desert (Williams 2001) and for nestlings of Desert Larks and Crested Larks from the Negev Desert (Shkedy and Safriel 1992) (Appendix D, Table D1, 

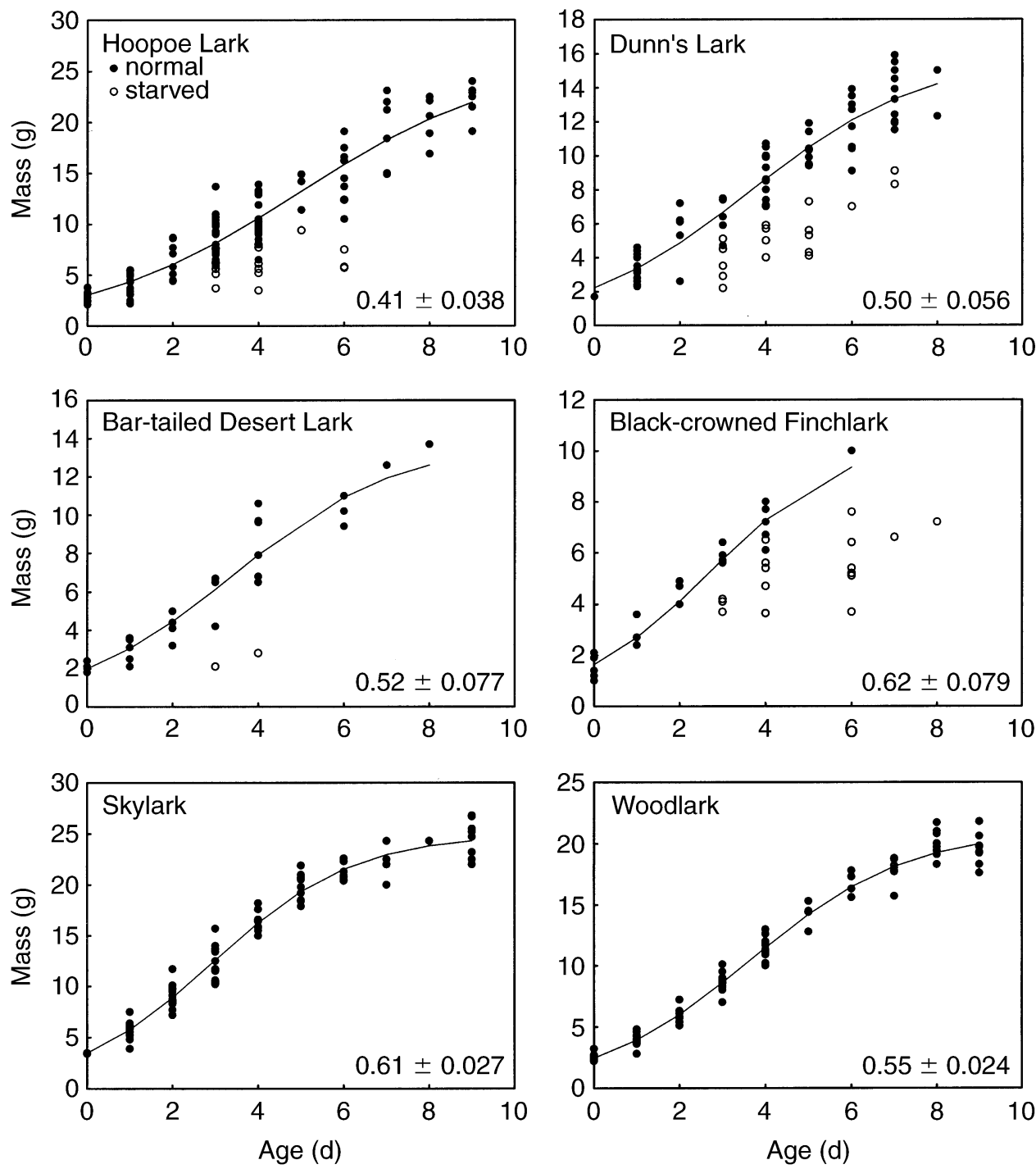

FIG. 3. The relationship between body mass and age of nestlings, and the growth constant $K$ (mean \pm 1 SE, reported in the lower right corner of each panel) for six species of larks. Day 0 is hatching day.

Fig. 4A). A regression model with growth rate constant as dependent variable and aridity and adult body mass as dependent variables, showed a decrease in growth rate with increasing aridity (slope $\pm 1 \mathrm{SE}=$ $0.115 \pm 0.044, t=2.63, P=0.04$ ), but no significant effect of adult body mass (slope $\pm 1 \mathrm{SE}=-0.005 \pm$ $0.003, t=1.84, P=0.12$ ). Phylogeny was not a significant factor affecting growth rate (TFSI, $P=$ $0.14)$.

\section{Energy and water budgets of the parent-brood complex}

A budget of energy requirements for parents and brood combined can be evaluated as $E_{\text {fam }}=2 \times \mathrm{FMR}_{\mathrm{par}}$ $+E_{\text {bro }}$, where FMR par is parental FMR (Fig. 1C, Table $1 \mathrm{~A})$ and $E_{\text {bro }}$ is the metabolizable energy requirements of the nestlings (Fig. 1F). $E_{\text {bro }}$ can be calculated as $n$
$\times\left(\mathrm{FMR}_{\text {chi }}+\mathrm{ET}_{\text {chi }}\right)$, where $n$ is the number of nestlings

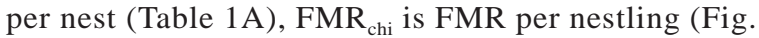
$1 \mathrm{E}$, Table $1 \mathrm{~B}$ ), and $\mathrm{ET}_{\text {chi }}$ is energy accumulated in new tissue. $\mathrm{ET}_{\text {chi }}$ can be estimated from the increase in wet mass per day (Appendix C, Table C1), and the energy density of wet tissue given by kilojoules per gram of wet mass $=3.51+4.82 \times u$, where $u$ is the proportion of adult mass attained (Weathers 1996). $E_{\text {fam }}$ averaged $261 \mathrm{~kJ} / \mathrm{d}$ for Hoopoe Lark, $164 \mathrm{~kJ} / \mathrm{d}$ for Dunn's Lark, $388 \mathrm{~kJ} / \mathrm{d}$ for Skylark, and $347 \mathrm{~kJ} / \mathrm{d}$ for Woodlark. Expressed per gram of family, these values equaled 1.94, $2.10,2.75$, and $2.80 \mathrm{~kJ} \cdot \mathrm{d}^{-1} \cdot \mathrm{g}^{-1}$, respectively, or about $27 \%$ lower in the desert species compared with the mesic-zone larks.

A family's water budget can be constructed as $W_{\text {fam }}$ $=2 \times \mathrm{WIR}_{\mathrm{par}}+\mathrm{WIR}_{\text {bro }}$, where WIR $\mathrm{War}$ is parental WIR (Fig. 2C, Table 1A), and $\mathrm{WIR}_{\text {bro }}$ is the water flux of 

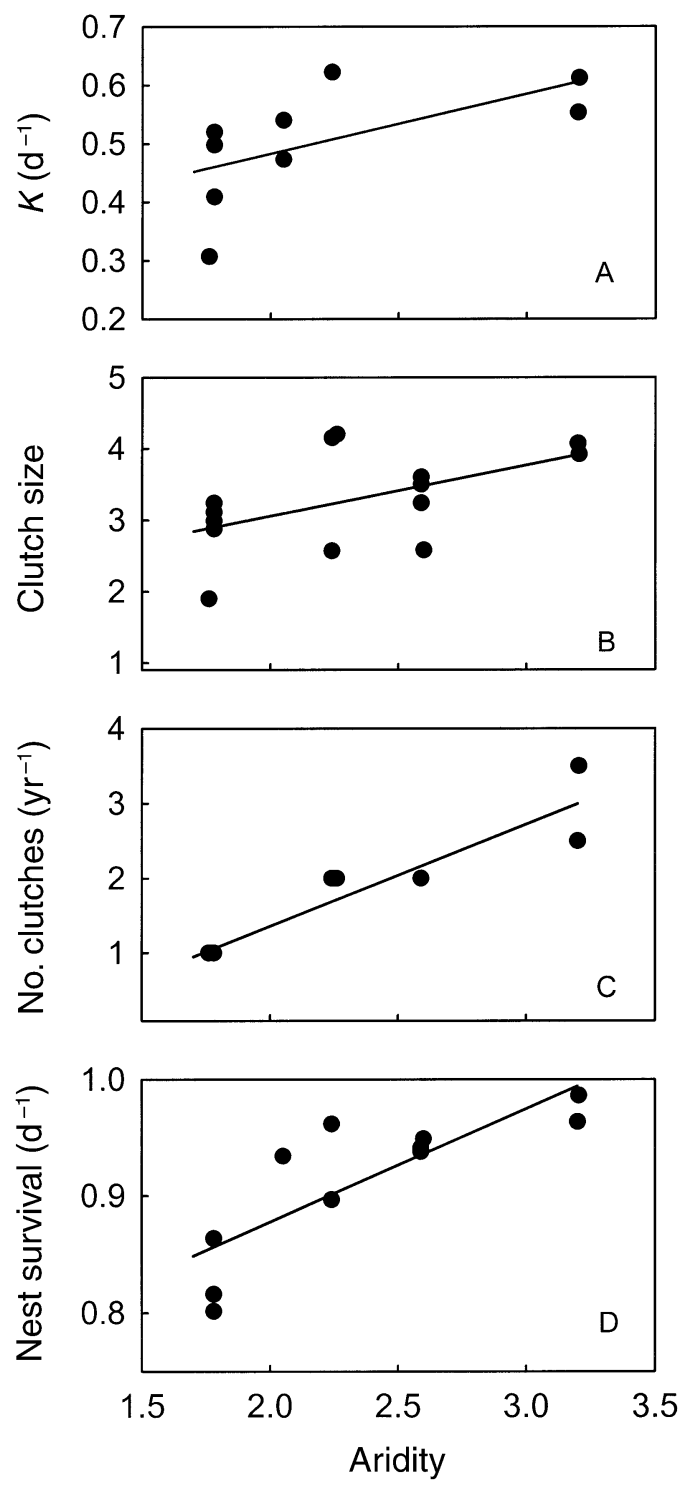

FIG. 4. (A) Growth constant $K$, (B) clutch size, (C) number of clutches, (D) and daily survival rate of larks along an aridity gradient. Data and sources are listed in Table D1 of Appendix D. The aridity index increases with decreasing aridity of the environment.

the nestlings calculated as $n \times\left(\mathrm{WIR}_{\text {chi }}+\mathrm{WT}_{\text {chi }}\right)$, with $n$ being the number of chicks per nest (Table 1A), $\mathrm{WIR}_{\text {chi }}$ the water flux per nestling (Fig. 2E, Table 1B), and $\mathrm{WT}_{\text {chi }}$ the amount of water accumulated in new tissue. $\mathrm{WT}_{\text {chi }}$ can be estimated from the increase in wet mass per day (Appendix C, Table C1) and the assumption that a 6-8 day old chick has a body water content of $69.4 \%$, the average based on the dilution spaces of the chicks injected with doubly labeled water. The absolute $W_{\text {fam }}$ equaled $46.6 \mathrm{~g} / \mathrm{d}$ for Hoopoe Lark, $37.3 \mathrm{~g} / \mathrm{d}$ for Dunn's Lark, $101.6 \mathrm{~g} / \mathrm{d}$ for Skylark, and $83.2 \mathrm{~g} / \mathrm{d}$ for Woodlark. Accounting for mass dif- ferences among species, $W_{\text {fam }}$ expressed per gram of family averaged $0.35,0.48,0.72$, and $0.67 \mathrm{~g} \cdot \mathrm{d}^{-1} \cdot \mathrm{g}^{-1}$, respectively. Families of the desert larks used $28-51 \%$ less water per gram than species from mesic areas.

\section{FMR and WIR along an aridity gradient:} conventional and phylogenetic analyses

We reanalyzed FMR and WIR of Dune Larks (Williams 2001), correcting for fractionation effects, and found an average FMR of $49.0 \pm 17.05 \mathrm{~kJ} / \mathrm{d}$ and WIR of $5.99 \pm$ $1.10 \mathrm{~g} / \mathrm{d}$ for adults (body mass $27.0 \pm 1.81 \mathrm{~g}, n=11$ ), and for nestlings at day 8 (mass $15.0 \mathrm{~g}$ ), a FMR of 25.7 $\mathrm{kJ} / \mathrm{d}$ and a WIR of $5.29 \mathrm{~g} / \mathrm{d}$, based on logistic equations. Adding these data to the results of the present study (six species, Table 1), we regressed species-average values of FMR and WIR against an aridity index. Lower values of this index indicate more extreme aridity. Conventional analyses showed that FMR adjusted for in body mass in grams and mass-adjusted WIR of adults decreased significantly with increasing aridity $\left(\mathrm{FMR}\right.$ in $\mathrm{kJ} \cdot \mathrm{d}^{-1} \cdot \mathrm{g}^{-0.96}, r^{2}$ $=0.96$, slope $\pm 1 \mathrm{SE}=0.93 \pm 0.082, P<0.0001, n=$ 7 ; WIR in $\mathrm{g} \cdot \mathrm{d}^{-1} \cdot \mathrm{g}^{-1.16}, r^{2}=0.83$, slope $\pm 1 \mathrm{SE}=0.13$ $\pm 0.026, P=0.004, n=7)$. The mass exponents were derived from regression equations based on the average values for the seven lark species and relating $\log$ (mass) to $\log (\mathrm{FMR})$ and $\log (\mathrm{WIR})$, respectively. For nestlings, mass-specific FMR and mass-specific WIR also decreased with increasing aridity, but the latter was not statistically significant (FMR in $\mathrm{kJ} \cdot \mathrm{d}^{-1} \cdot \mathrm{g}^{-1}, r^{2}=0.72$, slope $\pm 1 \mathrm{SE}$ $=0.38 \pm 0.120, P=0.03, n=6$; WIR in $\mathrm{g} \cdot \mathrm{d}^{-1} \cdot \mathrm{g}^{-1}, r^{2}$ $=0.65$, slope $\pm 1 \mathrm{SE}=0.18 \pm 0.065, P=0.054, n=$ $6)$. Using the TFSI, we found no significant phylogenetic effect for mass-adjusted FMR of adults $(P=0.09)$, but significant phylogenetic autocorrelation in the data for mass-adjusted WIR of adults $(P=0.04)$, and for massspecific FMR $(P=0.03)$ and mass-specific WIR of nestlings $(P=0.02)$. The latter results and the marginal insignificance of adult FMR prompted us to additionally analyze these data using PIC analysis. This analysis showed that adult mass-adjusted FMR and WIR decreased significantly with increasing aridity, confirming the results of the conventional analysis (PIC FMR, $r^{2}=0.97$, slope $\pm 1 \mathrm{SE}=0.93 \pm 0.078, \mathrm{df}=5, P<0.0001$; PIC WIR, $r^{2}=0.76$, slope $\pm 1 \mathrm{SE}=0.12 \pm 0.031$, df $=5$, $P=0.011)$. PIC analysis of the nestling data revealed trends of decreasing mass-specific FMR and WIR with increasing aridity, identical to the conventional analysis, but these trends were insignificant (PIC FMR, $r^{2}=0.62$, slope $\pm 1 \mathrm{SE}=0.33 \pm 0.129$, df $=4, P=0.07$; PIC WIR, $r^{2}=0.51$, slope $\pm 1 \mathrm{SE}=0.15 \pm 0.073$, df $=4$, $P=0.11)$.

\section{Clutch size and number of larks along an aridity gradient}

We combined information on clutch size and number of clutches per breeding season of larks from the Arabian Desert and The Netherlands with data from eight other lark species from the literature to test if 
clutch size and number of clutches varied with aridity (Appendix D, Table D1). When aridity increased, clutch size decreased (Fig. 4B, slope $\pm 1 \mathrm{SE}=0.746$ $\left.\pm 0.333, P=0.045, r^{2}=0.30, n=14\right)$ and number of clutches per season decreased (Fig. 4C, slope \pm 1 $\left.\mathrm{SE}=1.39 \pm 0.181, P<0.0001, r^{2}=0.87, n=11\right)$. On average, larks from hyperarid deserts have one clutch per year with 2.8 eggs, whereas species from mesic areas lay three clutches of 3.9 eggs per year. We determined if phylogeny might confound our analyses and found a marginally insignificant phylogenetic autocorrelation for clutch size (TFSI, $P=0.06$ ), but a significant autocorrelation for number of clutches (TFSI, $P=0.001$ ). Therefore, we also analyzed these correlations between aridity and clutch size and number of clutches using PIC. In these analyses, clutch size was not correlated with aridity, contradicting the conventional analysis (slope $\pm 1 \mathrm{SE}=$ $0.414 \pm 0.413, r^{2}=0.08, t=1.00, \mathrm{df}=10, P=$ $0.35)$, but number of clutches still decreased with increasing aridity, confirming the results of the conventional analysis (slope $\pm 1 \mathrm{SE}=1.37 \pm 0.271, r^{2}$ $=0.74, t=5.05$, df $=7, P=0.001)$.

\section{Nest predation along an aridity gradient}

We collated daily survival rates of nests for six species from the literature in addition to our own data on larks from the Arabian Desert and The Netherlands (Appendix D, Table D1, Fig. 4D). There was a marginal insignificant effect of phylogeny on the daily survival rates (TFSI, $P=0.08$ ). Using conventional and PIC analysis, we found that daily survival rate significantly increased with decreasing aridity (conventional, slope $\pm 1 \mathrm{SE}=0.0969 \pm 0.021, r^{2}=0.68, P=0.001, n=$ 12; PIC, slope $\pm 1 \mathrm{SE}=0.08875 \pm 0.02835, r^{2}=$ $0.50, t=3.13$, df $=10, P=0.01)$. Because the total nest period (the sum of laying, incubation, and nestling phase) is similar among all larks, daily survival rate directly reflects the probability that a nest survives until fledging. If we assume a total nest period of 24 days and use the regression equation to determine average daily survival rate, the probability that a lark nest in a hyperarid desert survives is about $2 \%$, compared with $87 \%$ for a nest in a mesic habitat.

\section{Discussion}

\section{An axis of aridity: correlates and constraints}

We have presented variation in physiological, demographic, and ecological variables along an environmental continuum of aridity, to add an extra dimension to the traditional comparison between desert and nondesert habitats, making the argument more compelling. The main environmental components along our continuum (primary productivity, rainfall, and temperature regime) provide simultaneous selective pressures reflected in decreasing availability of the resources energy, water, and time with increasing aridity. Because these factors vary in correlated fashion along our aridity gradient, we cannot meaningfully distinguish their separate effects. However, each factor separately and their combination might be expected to favor a set of adaptations characteristic of a more frugal lifestyle and slower pace of life (Ricklefs and Wikelski 2002), as supported by our results. Examples of the combined effects of these factors include: low food and water availability, which select for decreased energy and water expenditure and reduced growth rates; heat and lack of drinking water, which favor low metabolic heat production in order to reduce water expenditure for evaporative cooling; high temperatures, which limit time available for activity; and high nest predation, which results in selective benefits for small clutch sizes. Future work to separate the effects of the various selective pressures will require either an experimental approach in which one factor is manipulated at a time, such as food supplementation, or an expansion of the correlative studies to include environments with a different combination of selective pressures, such as the tropics where temperatures are high, but water is not at a premium.

\section{Field metabolic rate of parents}

This study supports the hypothesis that FMR and BMR decrease with increasing aridity in birds. The parallel increase between levels of FMR and BMR has been attributed to selection for the size of the metabolic machinery required to maintain levels of energy expenditure during the period when parents care for nestlings, the putative time of peak energy demand (Daan et al. 1990). However, when variation in body mass is taken into account, organ sizes do not differ among Hoopoe Larks, Dunn's Larks, Skylarks, and Woodlarks (Tieleman et al. 2003b). The differences in FMR and BMR among these species may be related to variation in tissue-specific metabolic rates of various organs rather than to their size, an avenue for future work. The reduced FMR in larks from the arid extreme could be partly attributable to low levels of BMR, but the physiological mechanisms that link BMR and FMR are poorly understood (Ricklefs 1996, Ricklefs et al. 1996). In addition, behavioral differences may contribute to the differences in FMR among larks. Larks in the desert are inactive during the middle part of the day, when it is too hot to forage (Tieleman and Williams 2002b), whereas the mesic-zone larks are active throughout the day.

\section{Water influx rate of parents}

WIR of larks decreased with increasing aridity. These results correspond with differences in TEWL previously found among the same species and are consistent with the hypothesis of reduced WIR in desert birds (Tieleman et al. 2002, Tieleman et al. 2003a). The association between TEWL and WIR is likely to result from both physiological adjustments, including 
increased skin resistance to evaporative water loss (Tieleman and Williams 2002a), and behavioral adaptations, including selection of favorable microclimates and reduced activity during hot hours (Williams et al. 1999, Tieleman and Williams 2002b). Larks in the desert spend a significant period of the hot part of the day at the nest, providing shade or even cooling the nestlings (Tieleman et al. 2003c). This behavior presumably requires a significant amount of water for evaporative cooling and makes the low WIR of these species more remarkable. One might predict that the proportions of evaporative and excretory water loss differ markedly between birds from the arid and mesic extremes of the aridity gradient, with larks from the latter group losing larger quantities of surplus water by excretion.

\section{Energy and water requirements of nestlings}

The energy and water demands placed upon the parents by the brood depend on the energy and water requirements per nestling and on the number of chicks in the nest. One might expect that nestlings with low energy and water requirements are favored by natural selection in environments where food and water are in short supply. In support of this idea, we found a decrease in FMR and WIR of nestlings with increasing aridity. In addition, growth rates decreased with increasing aridity and contributed to lowering the daily energy and water requirements of nestlings in more arid environments (Fig. 4A).

\section{Parental effort per nestling}

Larks from deserts expend less energy and use less water while rearing young than larks from temperate areas, but because their broods were smaller, expenditures per chick were the same (Figs. 1B and 2B). Parental energy expenditure and water use per chick may be viewed as an index of parental effort because it provides a total measure of the amount of energy and water required by a parent to provide resources to a nestling. However, it does not separate costs of parental self-maintenance from costs of work that is specifically carried out to raise the young, and therefore does not provide a prediction of the energy and water costs to rear an additional chick. Still, it is noteworthy that despite lower energy and water requirements per chick, parental energy and water expenditure to supply a chick's requirements does not vary along the aridity gradient. Parents in deserts may be constrained by low water availability that reduces their evaporative cooling capacity and forces them to minimize activity during the hot part of the day. The resulting narrow window of time available to provision the brood leads to a smaller total amount of food that can be gathered per day. Therefore, parental self-maintenance costs, although low per time unit in deserts, contribute a large proportion to the daily parental energy and water expenditure per chick.

\section{Growth rate, clutch size, and nest predation: Lack's dilemma}

With increasing aridity, nest predation increased, growth rate decreased, and clutch size decreased. This result does not support Lack's (1968) prediction that growth rates should increase with increasing risk of predation. We propose that food and water availability may have a larger selective influence on growth rate, overriding the effect of nest mortality. Low food and water availability should select for reduced overall daily energy and water requirements of the brood, a prediction that is confirmed by the combination of reduced metabolism and water loss per nestling, low growth rate, and small clutch sizes in arid environments. The combination of high nest predation, slow growth, and small broods is also found in birds from the tropics (Skutch 1966, Ricklefs 1979, Martin et al. 2000, Ghalambor and Martin 2001). Although food may not be intuitively assumed to be a limiting factor for reproduction in the tropics, the reduced daily energy requirements per nestling (Weathers 1992), in addition to their slow growth rate, potentially also indicates selection for lower food requirements of nestlings.

The more influential role of food availability than mortality on nestling growth rate does not contradict Lack's original idea that growth rate might be a compromise between food supply and mortality, but shifts the emphasis of his subsequent prediction from mortality to food supply. Along an aridity gradient, food supply and mortality are correlated, and distinguishing the effect of each factor separately is not possible without experiments.

\section{Energy and water budgets of the parent-brood complex: a life history perspective}

Compared with temperate environments, the daily energy and water budgets of a family of larks in the desert, where food and water are scarce, are markedly lower not only when expressed in absolute terms but also per gram of family mass (Figs. $1 \mathrm{~F}$ and $2 \mathrm{~F}$ ). The frugal use of energy and water in arid-zone families is the result of a combination of low parental and nestling FMR and WIR, slow growth, and small broods. Although in proximate terms the reduced energy and water budgets can be intuitively understood in light of the environmental conditions, our insights at the ultimate level are less complete. A central prediction of the evolutionary theory of life histories is that parental investment should vary directly with the fitness of current offspring and inversely with adult survival. If parental effort as measured by energy expenditure, water loss, and clutch size is correlated with parental investment, i.e., the fitness consequence of the parental effort (Trivers 1972, Daan and Tinbergen 1997, Tinbergen and Verhulst 2000), we would conclude that the fitness value of a single brood is lower for an arid-zone species than for a lark from 
mesic habitats and predict that an adult lark in the desert has a higher probability of survival. Insights into the physiological, ecological, and environmental factors affecting adult survival might provide the key to understanding how evolution has fashioned these distinct sets of physiological, behavioral, and demographic variables along an environmental aridity gradient.

\section{ACKNOWLEDGMENTS}

We thank Abdulrahman Khoja, Patrick Paillat, Stéphane Ostrowski, and the other staff at the National Wildlife Research Center, Taif, Saudi Arabia, for logistic support throughout this study. Wildlife research programs at the NWRC are possible through the generous support of HRH Prince Saud al Faisal and under guidance of A. Abuzinada of the National Commission of Wildlife Conservation and Development, Saudi Arabia. Vince Schuler and Riek van Noordwijk helped with fieldwork in Saudi Arabia. We are grateful to Wouter de Vlieger and Staatsbosbeheer for permission to work at the Aekingerzand, to Berthe Verstappen for conducting the isotope analyses so quickly, and to Serge Daan for commenting on an earlier draft. Comments by Tony Williams, John Speakman, and an anonymous reviewer improved the manuscript. Financial support for this study was made available by the Schuurman Schimmel van Outeren Foundation, the Schure Beijerinck Popping Foundation, the National Wildlife Research Center, and the National Science Foundation (IBN-0212092).

\section{Literature Cited}

Abouheif, E. 1999. A method for testing the assumption of phylogenetic independence in comparative data. Evolutionary Ecology Research 1:895-909.

Bennett, A. F. 1988. Structural and functional determinates of metabolic rate. American Zoologist 28:699-708.

Björklund, M. 1997. Are 'comparative methods' always necessary? Oikos 80:607-612.

Boyce, M. S., and C. M. Perrins. 1987. Optimizing great tit clutch size in a fluctuating environment. Ecology 68 : 142-153.

Bryant, D. M. 1988. Energy expenditure and body mass changes as measures of reproductive costs in birds. Functional Ecology 2:23-34.

Cheverud, J. M., M. M. Dow, and W. Leutenegger. 1985. The quantitative assessment of phylogenetic constraints in comparative analyses: sexual dimorphism in body weight among primates. Evolution 39:1335-1351.

Daan, S., D. Masman, and A. Groenewold. 1990. Avian basal metabolic rates: their association with body composition and energy expenditure in nature. American Journal of Physiology 259:R333-R340.

Daan, S., and J. M. Tinbergen. 1997. Adaptation of life histories. Pages 311-333 in J. R. Krebs and N. B. Davies, editors. Behavioural ecology. An evolutionary approach. Blackwell Science, Oxford, UK.

Drent, R. H., and S. Daan. 1980. The prudent parent: energetic adjustments in avian breeding. Ardea 68:225-252.

Emberger, L. 1955. Afrique du Nord-Ouest. Pages 219-249 in UNESCO, editor. Plant ecology: reviews of research. UNESCO, Paris, France.

Felsenstein, J. 1985. Phylogenies and the comparative method. American Naturalist 125:1-15.

Garland, T. Jr., P. H. Harvey, and A. R. Ives. 1992. Procedures for the analysis of comparative data using phylogenetically independent contrasts. Systematic Biology 41:18-32.
Gessaman, J. A., and K. A. Nagy. 1988. Energy metabolism: errors in gas-exchange conversion factors. Physiological Zoology 61:507-513.

Ghalambor, C. K., and T. E. Martin. 2001. Fecundity-survival trade-offs and parental risk-taking in bidrs. Science 292:494-497.

Gittleman, J. L., and M. Kot. 1990. Adaptation: statistics and a null model for estimating phylogenetic effects. Systematic Zoology 39:227-241.

Grafen, A. 1989. The phylogenetic regression. Philosophical Transactions Royal Society, Series B 326:199-257.

Harvey, P. H., and M. D. Pagel. 1991. The comparative method in evolutionary biology. Oxford University Press, Oxford, UK.

Johnson, D. H. 1979. Estimating nest success: the Mayfield method and an alternative. Auk 96:651-661.

Klaassen, M., and R. H. Drent. 1991. An analysis of hatchling resting metabolism: in search of ecological correlates that explain deviations from allometric relations. Condor 93:612-629.

Lack, D. 1968. Ecological adaptations for breeding in birds. Methuen, London, UK.

Leroi, A. M. 1994. What does the comparative method reveal about adaptation? American Naturalist 143:381-402.

Lifson, N., and R. McClintock. 1966. Theory of use of the turnover rates of body water for measuring energy and material balance. Journal of Theoretical Biology 12:4674.

Louw, G. N., and M. K. Seely. 1982. Ecology of desert organisms. Longman, London, UK.

MacMillen, R. E. 1990. Water economy of granivorous birds: a predictive model. Condor 92:379-392.

Martin, T. E., P. R. Martin, C. R. Olson, B. J. Heidingen, and J. J. Fontaine. 2000. Parental care and clutch sizes in North and South American birds. Science 287:14821485 .

Mayfield, H. F. 1975. Suggestions for calculating nest success. Wilson Bulletin 87:456-466.

Nagy, K. A. 1980. $\mathrm{CO}_{2}$ production in animals: analysis of potential errors in the doubly labeled water method. American Journal of Physiology 238:R466-R473.

Nagy, K. A., and D. P. Costa. 1980. Water flux in animals: analysis of potential errors in the tritiated water method. American Journal of Physiology 238:R454-R465.

Perrins, C. M., and D. Moss. 1975. Reproductive rates in the great tit. Journal of Animal Ecology 44:695-706.

Reeve, J., and E. Abouheif. 1999. Phylogenetic independence. Version 1.1. Department of Ecology and Evolution, State University of New York, Stony Brook, New York, USA.

Reznick, D. 1985. Costs of reproduction: an evaluation of the empirical evidence. Oikos 44:257-267.

Ricklefs, R. E. 1979. Adaptation, constraint, and compromise in avian postnatal development. Biological Reviews 54:269-290.

Ricklefs, R. E. 1996. Avian energetics, ecology, and evolution. Pages 1-30 in C. Carey, editor. Avian energetics and nutritional ecology. Chapman and Hall, New York, New York, USA.

Ricklefs, R. E., M. Konarzewski, and S. Daan. 1996. The relationship between basal metabolic rate and daily energy expenditure in birds and mammals. American Naturalist 147:1047-1071.

Ricklefs, R. E., M. Wikelski. 2002. The physiology/life history nexus. Tree 17(10):462-486.

Shkedy, Y., and U. N. Safriel. 1992. Nest predation and nestling growth rate of two lark species in the Negev Desert, Israel. Ibis 134:268-272.

Skutch, A. F. 1966. A breeding bird census and nesting success in Central America. Ibis 108:1-16. 
Speakman, J. R. 1997. Doubly labelled water. Chapman and Hall, London, UK.

SPSS. 1999. Systat. Version 10.0. SPSS, Chicago, Illinois, USA.

Stearns, S. C. 1992. The evolution of life histories. Oxford University Press, Oxford, UK.

Tieleman, B. I., and J. B. Williams. 2000. The adjustment of avian metabolic rates and water fluxes to desert environments. Physiological and Biochemical Zoology 73: 461-479.

Tieleman, B. I., and J. B. Williams. 2002a. Cutaneous and respiratory water loss in larks from arid and mesic environments. Physiological and Biochemical Zoology 75 : 590-599.

Tieleman, B. I., and J. B. Williams. 2002b. Effects of food supplementation on behavioral decisions of Hoopoe Larks in the Arabian Desert: balancing water, energy and thermoregulation. Animal Behaviour 63:519-529.

Tieleman, B. I., J. B. Williams, and P. Bloomer. $2003 a$. Adaptation of metabolism and evaporative water loss along an aridity gradient. Proceedings of the Royal Society of London, Series B 270:207-214.

Tieleman, B. I., J. B. Williams, and M. E. Buschur. 2002. Physiological adjustments to arid and mesic environments in larks (Alaudidae). Physiological and Biochemical Zoology 75:305-313.

Tieleman, B. I., J. B. Williams, M. E. Buschur, and C. R. Brown. 2003b. Phenotypic variation among and within larks along an aridity gradient: are desert birds more flexible? Ecology 84:1800-1815.

Tieleman, B. I., J. B. Williams, and G. H. Visser. 2003c. Variation in allocation of time, water and energy in Hoopoe Larks from the Arabian Desert. Functional Ecology, 17:869-876.

Tinbergen, J. M., and S. Verhulst. 2000. A fixed energetic ceiling to parental effort in the great tit? Journal of Animal Ecology 69:323-334.

Trivers, R. L. 1972. Parental investment and sexual selection. Pages 136-179 in B. Campbell, editor. Sexual selection and the descent of man. Heinemann, London, UK.

Visser, G. H., A. Dekinga, B. Achterkamp, and T. Piersma. 2000. Ingested water equilibrates isotopically with the body water pool of a shorebird with unrivaled water fluxes. American Journal of Physiology 279:R1795-R1804.

Visser, G. H., and H. Schekkerman. 1999. Validation of the doubly labeled water method in growing precocial birds: the importance of assumptions concerning evaporative water loss. Physiological and Biochemical Zoology 72: 740-749.

Weathers, W. W. 1992. Scaling nestling energy requirements. Ibis 134:142-153.

Weathers, W. W. 1996. Energetics of postnatal growth. Pages 461-496 in C. Carey. Avian energetics and nutritional ecology Chapman and Hall, New York, New York, USA.

Weathers, W. W., and K. A. Sullivan. 1989. Juvenile foraging proficiency, parental effort, and avian reproductive success. Ecological Monographs 59:223-246.

Westoby, M., M. R. Leishman, and J. M. Lord. 1995. On misinterpreting the "phylogenetic correction". Journal of Ecology 83:531-534.

Williams, G. C. 1966. Adaptation and natural selection. Princeton University Press, Princeton, New Jersey, USA. Williams, J. B. 1996. A phylogenetic perspective of evaporative water loss in birds. Auk 113:457-472.

Williams, J. B. 2001. Energy expenditure and water flux of free-living Dune Larks in the Namib Desert: a test of the re-allocation hypothesis. Functional Ecology 15:175185 .

Williams, J. B., and A. Prints. 1986. Energetics of growth in nestling savannah sparrows: a comparison of doubly labelled water and laboratory estimates. Condor 88:7483.

Williams, J. B., and B. I. Tieleman. 2001. Physiological ecology and behavior of desert birds. Pages 299-353 in V. Nolan and C. F. Thompson, editors. Current ornithology. Volume 16. Plenum Press, New York, New York, USA.

Williams, J. B., B. I. Tieleman, and M. Shobrak. 1999. Lizard burrows provide thermal refugia for larks in the Arabian desert. Condor 101:714-717.

Zar, J. H. 1996. Biostatistical analysis. Prentice Hall, Englewood Cliffs, New Jersey, USA.

\section{APPENDIX A}

Doubly labeled water methods are available in ESA's Electronic Data Archive: Ecological Archives E085-036-A1.

\section{APPENDIX B}

Ratios of field metabolic rate/basal metabolic rate (FMR/BMR) and water influx rate/total evaporative water loss (WIR/ TEWL), and a figure showing parental FMR and WIR expressed in multiples of BMR and TEWL are available in ESA's Electronic Data Archive: Ecological Archives E085-036-A2.

\section{APPENDIX C}

A table showing logistic growth curve variables is available in ESA's Electronic Data Archive: Ecological Archives E085036-A3.

\section{APPENDIX D}

A table showing aridity index, nestling growth constant $K$, clutch size and number, and daily nest survival rate for 14 species of larks is available in ESA's Electronic Data Archive: Ecological Archives E085-036-A4. 